\title{
Bronkopulmoner Displazi Tedavisinde Sistemik Steroid Kullanımı
}

\author{
Steroid Treatment in Bronchopulmonary Dysplasia
}

\author{
Selahattin Akar ${ }^{1}$, Sevilay Topçuoğlu ${ }^{1}$, Güner Karatekin ${ }^{1}$, Fahri Ovalı ${ }^{1}$ \\ 1. Zeynep Kamil Kadın ve Çocuk Hastalıkları Eğitim ve Araştırma Hastanesi, Yenidoğan Yoğun Bakım Ünitesi, İstanbul
}

\section{$\ddot{O Z Z E T}$}

Amaç: Bronkopulmoner displazi (BPD) oksijen ve pozitif basinçli ventilasyon ile tedavi edilen prematüre bebeklerde gelişen kronik bir akciğer hastallğılır. Bu çalışmada, BPD gelişen, sistemik steroid kullanılan olgularda tedavi etkinliğinin değerlendirilmesi amaçlanmıştır.

Gereç ve Yöntem: Çalışmaya 1 Ocak 2012 ile 31 Aralık 2012 tarihleri arasında Yenidoğan Yoğun Bakım Ünitesine yatırlarak izlenen, BPD gelişen ve solunum destek tedavisi gereken 18 prematüre bebek alındi. Steroid kullanım öncesi ve sonrasi solunum destek durumları değerlendirildi.

Bulgular: Hastaların gestasyon yaşları ortalama 26,81 $\pm 1,87$ (24-31) hafta, yatış süresi ortalama $77,5 \pm 12,92$ (23-142) gün, steroid tedavi süresi orta-

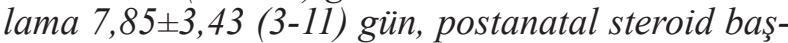

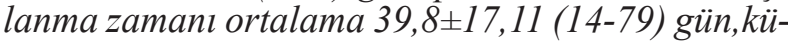
mülatif steroid dozu ortalama 0,65 $\pm 0,27(0,3-1,2)$ $\mathrm{mg} / \mathrm{kg}$, steroid başlandiktan sonra ekstube olduğu gün ortalama 7,82 $\pm 8,14$ (1-28), steroid başlandiktan sonra nazal CPAP'in (Continuous Positive Airway Pressure) kesildiği gün ortalama 16,6 $\pm 14,4$ (4-61) idi. Steroid başlandığında 14 hasta entübe, 4 hasta nazal CPAP tedavisi almaktaydl. Steroid sonlandığında nazal CPAP alan 4 hastadan birinin oksijeni kesilmiş, biri hood içi oksijenle izlenmeye geçmiş, biri kövöz içi oksijenle izleme geçmiş, biri nazal CPAP'ta izlenmeye devam edilmişti. Entübe olan 14 hastadan 5'i nazal CPAP'a geçmiş, 1 'i küvöz içi oksijenle izleme alınmış, 1 'i hood içi oksijen ile 7 'si entübe olarak izlenmeye devam edilmişti.

Sonuç: Bronkopulmoner displazi tedavisinde steroidler birçok merkezde farklı şekilde kullanılmasına rağmen kısa dönemdeki etkileri tartışmalıdır. Bu konuyla ilgili randomize kontrollü çalışma yapılması birçok nedenden dolayı zor olduğu için ancak bildirilen vaka grupları ile karar vermek gerekecektir.

Anahtar Kelimeler: bronkopulmoner displazi, steroid, kronik akciğer hastalı̆̆

\section{ABSTRACT}

Objective: Bronchopulmonary Dysplasia (BPD) is a chronic lung disease of premature newborns treated with positive pressure ventilation and oxygen. In this study we aimed to evaluate the efficiency of steroid usage in BPD patients.

Material and Method: Eighteen preterm newborn born between 01.01.2012 and 21.12.2012 were enrolled to the study. The oxygen need before and after treatment was evaluated.

Results: The mean gestational age of patients were $26.81 \pm 1.87$ (24-31) weeks, length of hospital stay $77.5 \pm 12.92$ (23-142) days, length of steroid treatment 7.85 \pm 3.43 (3-11) days, starting with treatment $39.8 \pm 17.11$ (14-79) days, mean cumulative dosage of steroid $0.65 \pm 0.27(0.3-1.2) \mathrm{mg} / \mathrm{kg}$, extubation day after treatment 7.82 \pm 8.14 (1-28), leaving CPAP after treatment 16.6 \pm 14.4 (4-61). At the beginning of the treatment 14 patients were intubated and 4 were in CPAP. After treatment one of the four patients in CPAP stayed in CPAP, one needed oxygen in hood, one in free flow and the other no more oxygen treatment, from 14 intubated patients 5 needed nasal CPAP, one oxygen in hood, one in free flow and the other 7 stated intubated.

Discussion: Although steroids are used in many centers in different therapy schedules, short term effects are still controversial. Since many factors confine to perform a randomized controlled study on this subject, observational studies are very important to gather more information.

Keywords: bronchopulmonary dysplasia, steroid, chronic lung disease

\footnotetext{
İletişim Bilgileri:

Yazışmadan Sorumlu Yazar: Selahattin Akar

Yazışma Adresi: Zeynep Kamil Kadın ve Çocuk Hast. Eğt. ve Arş. Hast., Yenidoğan Yoğun Bakım Ünitesi, İstanbul E-mail: selahattinakar2001@yahoo.com

Makalenin Geliş Tarihi: 25.08.2014

Makalenin Kabul Tarihi: 20.09.2014
} 


\section{GİRIŞ}

Bronkopulmoner displazi, 32 gebelik haftas1 ve 1500 gramdan küçük bebeklerin uzun süreli izleminde görülen kronik akciğer hastal1ğıdır. İlk kez 1967 yılında Northway ve ark.'ları (1) tarafından tanımlanmış ve bronkopulmoner displazi terimi kullanılmıștır. Daha sonra ventilasyon ölçütleri 28. günde oksijen bağımlılığı ve sıra dıșı akciğer grafi bulguları olarak değiștirilmiștir. 2001 y1lında Jobe ve Bancalari "postkonsepsiyonel" 36 gebelik haftası veya hastaneden çıkıştaki oksijen gereksinimini ölçüt olarak almıș ve bu yeni BPD tanımı literatürde kabul edilmiştir (2). BPD etyopatogenezi tam olarak aydınlatılamamıstır ancak multifaktöriyel olduğu düşünülmektedir. Günümüzde eskiye oranla daha düşük basınç ve daha az konsantrasyonlarda oksijen uygulandığı için BPD'nin patogenezinde majör etkenler olarak kabul edilen barotravma ve oksijen toksisitesi daha geri plana düşmüștür. Bugün için en önemli iki faktör prematürite ve enflamasyondur (3). Kolsuz ve arkadaşlarının yaptığı çalışmada erken membran rüptürü (EMR) olan hastalarda EMR olmayanlara göre BPD sıklığının daha fazla olduğu bildirilmiștir (4). Bu nedenle de etken faktörlere karşı koruyucu önlemlere ek olarak enflamasyon sürecinin durdurulması amaçlı, gerek sistemik gerekse inhale steroidler kullanılmaktadır $(5,6)$. Bu çalıșmada BPD nedeniyle steroid başlanan ve steroid kullanım öncesi ve sonrasi solunum destek durumlarının değerlendirilmesi amaçlanmıştır.

\section{GEREÇ VE YÖNTEM}

Çalışmaya 1 Ocak 2012 ile 31 Aralık 2012 tarihleri arasında Yenidoğan Yoğun Bakım Ünitesine yatırılarak izlenen ve BPD gelișen 26 prematüre bebek retrospektif olarak alındı. BPD tanısı için en az 28 gün oksijen gereksinimi kriter alındı. Çalıșmaya konjenital anomali, konjenital kalp hastalığı olan ve steroid tedavisi almaktayken nekrotizan enterokolit ve sepsis gelișen hastalar alınmadı. Bunlardan hood ile oksijen almakta olan 6 hasta ile küvöz içi oksijen almakta olan 2 hasta değerlendirmeye alınmadi. Hastalarımıza $0,5 \mathrm{mg} / \mathrm{kg} / \mathrm{gün}$ 2 doz, 3 gün ve başlangıç dozu $0,1 \mathrm{mg} / \mathrm{kg} /$ gün (3 gün), devam dozu 0,075 mg/kg/gün (3 gün), $0,05 \mathrm{mg} / \mathrm{kg} /$ gün (5 gün) olan iki farklı protokol uyguladık. Steroid kullanım öncesi ve sonrası solunum destek durumları değerlendirildi. Hastaların gestasyon yaşları, yatıs süresi, steroid aldığı toplam gün sayısı, steroid başlandığında düzeltilmiş gestasyonel hafta, kümülatif steroid dozu, steroid başlandıktan sonra ekstübe olduğu gün, steroid başlandıktan sonra nazal CPAP'ın kesildiği gün, steroid başlandıktan sonra oksijenin kesildiği gün hesaplandı (Tablo 1).

\begin{tabular}{|c|c|c|c|}
\hline & Minimum & Maksimum & $\begin{array}{l}\text { Ortalama } \\
\quad \pm S D\end{array}$ \\
\hline Gebelik Süresi (Hafta) & 24 & 31 & $26,81 \pm 1,87$ \\
\hline Yatış Süresi (gün) & 23 & 142 & $77,5 \pm 12,92$ \\
\hline Steroid kullanım süresi (gün) & 3 & 11 & $7,85 \pm 3,43$ \\
\hline $\begin{array}{l}\text { Steroid başlandığında } \\
\text { düzeltilmiş gestasyonel hafta }\end{array}$ & 27,4 & 37,4 & $32,5 \pm 2,84$ \\
\hline $\begin{array}{l}\text { Postnatal şteroid başlanma } \\
\text { zamanı (gün) }\end{array}$ & 14 & 79 & $39,8 \pm 17,11$ \\
\hline $\begin{array}{l}\text { Kümülatif Steroid Dozu } \\
\text { (mg/kg) }\end{array}$ & 0,3 & 1,2 & $0,65 \pm 0,27$ \\
\hline $\begin{array}{l}\text { Steroid sonrası ekstubasyon } \\
\text { süresi(gün) }\end{array}$ & 1 & 28 & $7,82 \pm 8,14$ \\
\hline $\begin{array}{l}\text { Steroid sonrası CPAP'ten } \\
\text { ayrılma süresi (gün) }\end{array}$ & 4 & 61 & $16,6 \pm 14,4$ \\
\hline $\begin{array}{l}\text { Steroid sonrası oksijen } \\
\text { kesilme süresi (gün) }\end{array}$ & 3 & 89 & $25,9 \pm 24,12$ \\
\hline
\end{tabular}

SD: Standart Deviasyon

\section{BULGULAR}

Hastaların gestasyon yaşları ortalama 26,81 $\pm 1,87$ (24-31) hafta, yatış süresi ortalama $77,5 \pm 12,92$ (23-142) gün, steroid tedavi süresi ortalama 7,85 $\pm 3,43$ (3-11) gün, postnatal steroid başlanma zamanı ortalama $39,8 \pm 17,11$ (14-79) gün, kümülatif steroid dozu ortalama $0,65 \pm 0,27$ $(0,3-1,2) \mathrm{mg} / \mathrm{kg}$, steroid başlandiktan sonra ekstube olduğu gün ortalama 7,82 $\pm 8,14$ (1-28), steroid başlandıktan sonra nazal CPAP'ın (Continuous Positive Airway Pressure) kesildiği gün ortalama 16,6 $\pm 14,4$ (4-61) idi (Tablo 1).

Steroid bașlandığında 4 hasta nazal CPAP tedavisi almakta, 14 hasta entübe olarak izlenmekteydi (Tablo 2). Steroid sonlandiğında nazal CPAP alan 4 hastadan birinin oksijeni kesilmiş, biri hood içi oksijenle izlenmeye geçmiş, biri kuvöz içi oksijenle izleme geçmiş,biri nazal CPAP'ta izlenmeye devam edilmişti. Entübe olan 14 hastadan 5'i nazal CPAP'a geçmiş, 1'i küvöz içi oksijenle izleme alınmış, 1 'i hood içi oksijen ile 7'si entübe olarak izlenmeye devam edilmiş olarak saptandı (Tablo 2).

\begin{tabular}{|c|c|c|c|c|c|c|c|}
\hline \multicolumn{2}{|c|}{$\begin{array}{l}\text { STEROID } \\
\text { ÖNCESI }\end{array}$} & \multicolumn{6}{|c|}{ STEROID SONRASI } \\
\hline & & SIMV & CPAP & HOOD & $\begin{array}{l}\text { KüVÖZ } \\
\text { Içi O }\end{array}$ & $\begin{array}{c}\text { KESiLMiŞ } \\
\mathrm{O}_{2}\end{array}$ & TOPLAM \\
\hline SIMV & 14 & 7 & 5 & 1 & 1 & 0 & 14 \\
\hline CPAP & 4 & 0 & 1 & 1 & 1 & 1 & 4 \\
\hline TOPLAM & 18 & 7 & 6 & 2 & 2 & 1 & 18 \\
\hline
\end{tabular}

SIMV: Synchronized Intermittent Mandatory Ventilation,

CPAP: Continuous Positive Airway Pressure. 


\section{TARTIŞMA}

Bronkopulmoner displazi 32 GH'den kücük bebeklerin önemli bir hastalığıdır. Yaşatılan bebeklerde BPD siklığg Kanada' dan Lee ve ark.' ları tarafindan (7) \%26, National Institute of Child Health and Human Development Neonatal Reserch Network NICHHD'nin çalışmasinda $\% 3-43$, ortalama $\% 23$ olarak bildirilmiștir (8). Ülkemizden Özkan ve ark.'ları (9) birimlerinin BPD sıklığını \%30 olarak bildirirken bu olguların \%36'sinin 28 GH, \%41,9'unun 1000 gr altındaki bebekler olduğunu belirtmişlerdir. Ünitemizde yapılan bir çalıșmada ise BPD sıklığı \%23 olarak bildirilmiștir. Aynı çalıșmada doğum ağırlığ1 750 gr altı olan bebeklerde $\% 100,750-999$ gr olan bebeklerde \%56, 10001249 olan bebeklerde $\% 55,1250-1500$ gr olan bebeklerde $\% 21$ olarak belirlenmiştir (10).

Bronkopulmoner displazi patogenezinde inflamasyonun önemli bir yer tuttuğunun gösterilmesi farmakolojik modülasyon ile BPD'nin önlenebileceği fikrini doğurmuştur (11). Postnatal steroid uygulamalarının BPD'li bebeklerde ekstübasyon başarısını artırdığını bildiren 1990'lı y1llardaki yayınlarla birlikte özellikle deksametazon yenidoğan yoğun bakım ünitelerinde BPD'nin gelişmesini önleyici amaçlı popüler bir ilaç olmuştur (12). Takip eden y1llarda büyük serili çalışmalarda steroid kullanımına bağlı kısa ve uzun dönem komplikasyonların bildirilmeye başlanması steroid kullanımı hakkında soru işaretlerinin oluşmasına neden olmuştur. Steroidlerin özellikle nörogelişim üzerine olumsuz etkilerinin gözlenmesi, kullanım alanının kısıtlanması gerekliliğini ortaya koymuştur. Postnatal steroid uygulamalarının ilk başlandığında akciğer fonksiyonlarında gözlenen klinik düzelmeler, kısa dönem komplikasyonlarının göz ardı edilmesine neden olmuştur. Vermont-Oxford Network'a üye 500 dolayında yenidoğan yoğun bakım ünitesinde, 1996-1998 yıllarında çok düşük doğum ağırlıklı bebeklerin yaklaşık \%25'inde postnatal steroid kullanıldığ 1 bildirilmiştir (13). Ancak nörolojik yan etkilerinin gözlenmesi bu ilacı tartışmalı hale getirmiştir ve 2002 y1lında, Amerikan Pediatri Akademisi ve Kanada Pediatri Birliği ortak bir bildiri yayınlayarak postnatal steroid kullanımının s1nırlandırılması gerektiğini vurgulamışlardır $(14,15)$. Bronkopulmoner displazide steroidler ventilatorden erken ayrılmayı hedefleyen çalışmalarda 0-4 gün, 7-14 gün, 21 günden sonra şeklinde kullanılmıştır. Ancak izlem çalışmalarında ciddi nörogelişimsel komplikasyonlardan başta beyin felcinin görülmesiyle çok erken, erken, orta erken uygulamalar bırakılmış, gerekçesi olanlarda geç dönem kullanımı önerilmiştir $(23,24)$. Steroidlerle ilgili çok sayıda çalışma olmasına rağmen hangi dozda uygulanması konusu tartışmalıdır (16-18) (Tablo 3).
Tablo 3. Sistemik steroid kullanım doz şemaları.

\begin{tabular}{|c|c|c|c|}
\hline Yazar, Yıl & $\begin{array}{l}\text { Kulla- } \\
\text { nılan } \\
\text { Steroid }\end{array}$ & $\begin{array}{l}\text { Başlangıç } \\
\text { Dozu }\end{array}$ & Devam Dozu ve Süre \\
\hline $\begin{array}{l}\text { Doyle (19), } \\
2006\end{array}$ & $\begin{array}{l}\text { Deksa- } \\
\text { metazon }\end{array}$ & $\begin{array}{l}0,15 \mathrm{mg} / \mathrm{kg} / \\
\text { gün (3 gün) }\end{array}$ & $\begin{array}{c}0,1 \mathrm{mg} / \mathrm{kg} / \mathrm{gün} \text { (3 gün), } \\
0,05 \mathrm{mg} / \mathrm{kg} / \mathrm{gün} \text { (2 gün), } \\
0,02 \mathrm{mg} / \mathrm{kg} / \text { gün (2 gün); } \\
\text { toplam 0,89 mg/kg } 10 \\
\text { günde }\end{array}$ \\
\hline $\begin{array}{l}\text { Smolkin } \\
(18), 2008\end{array}$ & $\begin{array}{l}\text { Betame- } \\
\text { tazon }\end{array}$ & $\begin{array}{l}0,1-0,2 \mathrm{mg} / \\
\text { kg/gün } \\
\text { (5 gün) }\end{array}$ & $\begin{array}{l}\text { Postnatal 3-6. haftada baş- } \\
\text { lanır, toplam } 5 \text { gün }\end{array}$ \\
\hline $\begin{array}{l}\text { Bhandari } \\
(17), 2008\end{array}$ & $\begin{array}{l}\text { Oral } \\
\text { prednizo- } \\
\text { Ion }\end{array}$ & $\begin{array}{l}2 \mathrm{mg} / \mathrm{kg} / \mathrm{gün} \\
\text { (5 gün) }\end{array}$ & $\begin{array}{c}1 \mathrm{mg} / \mathrm{kg} / \mathrm{gün} \text { (3 gün), } 1 \mathrm{mg} / \\
\mathrm{kg} / \mathrm{gün} \text { aşırı ( } 3 \text { gün), ar- } \\
\text { dından gerekirse azaltarak } \\
\text { kesilme }\end{array}$ \\
\hline $\begin{array}{l}\text { Ohlsson } \\
(20), 1992\end{array}$ & $\begin{array}{l}\text { Deksa- } \\
\text { metazon }\end{array}$ & $\begin{array}{l}0,5 \mathrm{mg} / \mathrm{kg} / \\
\text { gün } \\
\text { (3 gün) }\end{array}$ & $\begin{array}{c}0,3 \mathrm{mg} / \mathrm{kg} / \mathrm{gün} \text { (3 gün), 0,2 } \\
\mathrm{mg} / \mathrm{kg} / \mathrm{gün} \text { (3 gün) ve } 0,1 \\
\mathrm{mg} / \mathrm{kg} / \text { gün (3 gün) }\end{array}$ \\
\hline $\begin{array}{l}\text { Avery (21), } \\
1985\end{array}$ & $\begin{array}{l}\text { Deksa- } \\
\text { metazon }\end{array}$ & $\begin{array}{l}0,5 \mathrm{mg} / \mathrm{kg} / \\
\text { gün } \\
\text { (3 gün) }\end{array}$ & $\begin{array}{c}\text { 0,3 mg/kg/gün ( } 3 \text { gün), ar- } \\
\text { dından her } 3 \text { günde bir doz } \\
\% 10 \text { azaltılarak } 0,1 \mathrm{mg} / \\
\mathrm{kg} \text { a ulaşılır, sonar da gün } \\
\text { aşırı } 1 \text { hafta kullanılarak } \\
\text { kesilir }\end{array}$ \\
\hline $\begin{array}{l}\text { Powell (22), } \\
2006\end{array}$ & $\begin{array}{l}\text { Deksa- } \\
\text { metazon }\end{array}$ & $\begin{array}{c}0,25 \mathrm{mg} / \mathrm{kg} / \\
\mathrm{doz}\end{array}$ & $\begin{array}{c}\text { Günde } 2 \text { doz, toplam } 6 \text { doz } \\
\text { (iv veya oral) }\end{array}$ \\
\hline $\begin{array}{l}\text { Powell (22), } \\
2006\end{array}$ & $\begin{array}{l}\text { Deksa- } \\
\text { metazon }\end{array}$ & $\begin{array}{c}0,25 \mathrm{mg} / \mathrm{kg} / \\
\mathrm{doz} \\
12 \text { saatte bir } \\
(10 \mathrm{doz})\end{array}$ & $\begin{array}{c}0,15 \mathrm{mg} / \mathrm{kg} / \mathrm{doz} 12 \text { saatte } \\
\text { bir (16 doz), 0,07 mg/kg/ } \\
\text { doz } 12 \text { saatte bir }\end{array}$ \\
\hline
\end{tabular}

Doz ve süre konusunda fikir birliği sağlanmamasına rağmen 2-3 günde cevap alınmayan hastalarda tedavinin sonlanmasi ve dramatik yanıt gözlenenlerde de kisa sürede (7-10 gün) tedavinin azaltılarak kesilmesi de önerilmektedir $(23,24)$. Lex w.ve arkadaşlarının yaptığ1 çalışmada BPD nedeniyle entübe olarak izlenen ve steroid başlanan 35 hastanın 3.günde 23 , 7.günde 17 ve 10.gün sonunda 14 hastanın hala entübe olduğu olduğu belirtilmiş ve steroid sonrası ekstübasyon başarısı \%60 olarak değerlendirilmiştir (25). Walther ve arkadaşlarının yaptığı çalışmada gebelik haftası 24-32 hafta olan BPD nedeniyle mekanik ventilatorde entübe olarak izlenen 36 hastaya steroid tedavisi (0,2 mg/kg/gün, 2 doz, 14 gün) başlanmış ve steroid sonrası hastaların \%76'sinın ekstübe olduğu belirtilmiş (26). Benzer şekilde Doyle ve arkadaşlarının yaptığ sonrası ekstübasyon başarısı \%60 olarak belirtilmiştir (19). Bizim çalışmamızda steroid sonrası ekstübasyon başarısı \%50 idi. Ekstübasyon başarımızın literatür verilerinden daha az olmasını, steroid başlanan vaka sayımızın daha az olmasından kaynaklanabileceğini düşündük. 
Sonuç olarak BPD tedavisinde steroidlerin birçok merkezde farklı şekilde kullanılmasına rağmen kısa dönemdeki etkileri tartışmalıdır. $\mathrm{Bu}$ konuyla ilgili randomize kontrollü çalışma yapılması birçok nedenden dolayı zor olduğu için ancak bildirilen vaka grupları ile karar vermek gerekecektir. Diğer yandan steroidlerin uzun süreli yan etkileri de dikkate alındığında her hastaya rutin uygulanabilecek kadar masum olmadıklarını, kullanım kararının vaka bazında irdelenmesi gerektiğini söylemek doğru olacaktır.

\section{KAYNAKLAR}

1. Northway WH Jr, Rosan RC, Porter DY. Pulmonary disease following respirator theraphy of membrane disease. $N$ Engl J Med 1967; 276: 357-68.

2. Jobe AH, Bancalari E. Bronchopulmonary dysplasia. Am j Respir Crit Care Med 2001; 163: 1723-9.

3. Koç E. Yeni Bronkopulmoner Displazi. T Klin J Ped 2004; 2:396-402.

4. Kolsuz D.L,Demirel B,Gürsoy T,Karatekin G,Ovalı F.Erken Membran Rüptürünün Preterm Bebeklerde Morbidite ve Mortalite Üzerine Etkisinin Araştırılması.Zeynep Kamil Tıp Bülteni 2013:44:221-226.

5. Zimmerman JJ, Gabbert D, Shivpuri C, Kayata S, Miller J, Ciesi $\neg$ elski W. Meter-dosed, inhaled beclomethasone initiated at birth to prevent bronchopulmonary dysplasia. Pediatr Crit Care Med 2000;1:140-145.

6. Hallman M, Peltoniemi O, Saarela T. Earlyneonatal hydrocortisone: study rather than treat. Pediatrics 2006;118:2540-2542.

7. Lee SK, McMillan DD, Ohlson A, et al. Variations in practice and outcomes in the Canadian NICU Network: 1996-1997. Pediatrics 2000; 106:1070-9.

8. Lemons JA, Bauer CR, Oh W, et al. Very low birth weight outcomes of the National Institute of Child Health and Human Development Neonatal Reserch Network, January 1995 Through December 1996. Pediatrics 2001: 107 (1): E1.

9. Ozkan H, Koksal N, Cetinkaya M, Canitez Y. Risk Factors for Bronchopulmonary Dysplasia. Guncel Pediatri 2008; 6: 66-71.

10. Kurt H. Bronkopulmoner Displazi sıklı̆̆l,Tıpta uzmanlı tezi., İstanbul (2012).

11. Eichenwald EC, Stark AR. Are postnatal steroids ever justified to treat severe bronchopulmonary dysplasia? Arch Dis Child Fetal Neonatal Ed 2007;92:334-337.

12. Cummings JJ, D'Eugionio DB, Gross SJ. A controlled trial

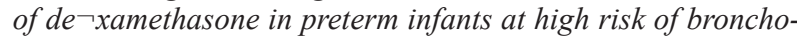
pulmo $\neg$ nary dysplasia. N Engl J Med 1989;320:1505-1510.
13. Walsh MC, Yao Q, Horbar JD, Carpenter JH, Lee Sk, Ohlsson A. Changes in the use of postnatal steroids for BPD in 3 large neonatal networks. Pediatrics 2006;118:1328-1335.

14. American Academy of Pediatrics, Canadian Paediatric Society. Postnatal corticosteroids to treat or prevent chronic lung disease in preterm infants. Pediatrics 2002;109:330-338.

15. Canadian Paediatric Society. Postnatal corticosteroids to treat or prevent chronic lung disease in preterm infants. J Paediatr Child Health 2002;7:20-28.

16. Powell K, Kerkering KW, Barker G, Rozycki HJ. Dexamethasone dosing, mechanical ventilation and the risk of cerebral palsy. J Ma $\neg$ ternal Fetal Neonatal Med 2006;19:43-48.

17. Bhandari A, Schramm CM, Kimble C, Pappagallo M, Hussain N. Effect of a short course of prednisolone in infants with oxygen dependent bronchopulmonary dysplasia. Pediatrics 2008; 121:344-349.

18. Smolkin T, Steinberg M, Sujov E, Mezer E, Tamir A, Makhoul $I R$. Late postnatal systemic steroids predispose to retinopathy of prematurity in very-low-birth-weight infants: a comparative study. Acta Paediatrica 2008;97:322-326.

19. Doyle LW, Davis PG, Morley CJ, McPhee A, Carlin JB: DART Study Investigators. Low dose dexamethasone facilitates extubati $\neg$ on among chronically ventilator-dependent infants: A multicenter, international, randomized, controlled trial. Pediatrics 2006; 117:75-83.

20. Ohlsson A, Calvert SA, Hosking M, Shennan AT. Randomized controlled trial of dexamethasone treatment in very-lowbirth-weight infants with ventilator-dependent chronic lung disease. Acta Paediatr 1992;81:751-756.

21. Avery GB, Fletcher AB, Kaplan M, Brudno DS. Controlled trial of dexamethasone in respirator-dependent infants with broncho-pulmonary dysplasia. Pediatrics 1985;75:106-111.

22. Powell K, Kerkering KW, Barker G, Rozycki HJ. Dexamethasone dosing, mechanical ventilation and the risk of cerebral palsy. J Ma ternal Fetal Neonatal Med 2006;19:43-48.

23. Walsh MC, Yao Q, Horbar JD, Carpenter JH, Lee Sk, Ohlsson A. Changes in the use of postnatal steroids for BPD in 3 large neonatal networks. Pediatrics 2006;118:1328-1335.

24. Eichenwald EC, Stark AR. Are postnatal steroids ever justified to treat severe bronchopulmonary dysplasia? Arch Dis Child Fetal Neonatal Ed 2007;92:334-337.

25. Lex W. Doyle, Peter G. Davis, Colin J. Morley, Andy McPhee and John B. Carlin. Low-Dose Dexamethasone Facilitates Extubation Among Chronically Ventilator-Dependent Infants: A Multicenter, International, Randomized, Controlled Trial. Pediatrics 2006;117;75.

26. Walther FJ, Findlay RD, Durand M. Adrenal suppression and extubation rate after moderately early low-dose dexamethasone therapy in very preterm infants. Early Hum Dev.2003;74(1):37-45. 